\title{
The Effect of Perceived Uncertainty on Competitive Behavior
}

\author{
Duncan James Drewry *a \&achary Reese $e^{b}$ \\ ${ }^{a}$ Weinberg Institute for Cognitive Science, University of Michigan, Ann Arbor, MI \\ ${ }^{b}$ Department of Psychology, University of Michigan, Ann Arbor, MI \\ https:/ / doi.org/10.33697/ ajur.2021.049 \\ Student:ddrewry@umich.edu* \\ Mentors:_reese@umich.edu*
}

\begin{abstract}
How do people behave in the face of uncertainty? Some studies suggest that even when they are unaware of how others will behave, people default to cooperative behavior; however, other research suggests that uncertainty leads to more competitive behavior. Little research has examined how individual differences moderate such behavioral decisions. This study proposes that a stable (dispositional) sense of justice may, ironically, lead to more competitive behavior. Specifically, people who score highly in belief in a just world, system justification, and religiosity, and low in ambiguity tolerance may be more inclined to compete rather than cooperate because they believe people who experience positive outcomes deserve those outcomes regardless of the means taken to achieve them. Across two studies, participants $(N=288)$ engaged in a prisoner's dilemma game - a task where they must choose to compete or cooperate — and completed the aforementioned individual difference measures. Results show that people tended to cooperate, but those high in system justification and belief in a just world were more likely to compete. In other words, people with a strong sense of cosmic justice were likely to exhibit competitive behavior under uncertain conditions.
\end{abstract}

\section{KEYWORDS}

Ambiguity Tolerance; Competition; Cooperation; Just World Beliefs; Prisoner's Dilemma; Prosocial Behavior; Religiosity; System Justification; Uncertainty

\section{INTRODUCTION}

With the rise of the COVID-19 pandemic, economic turmoil, and the threat of international conflict, our society lives with a great amount of daily uncertainty. Amidst this uncertainty, people must decide how to interact with one another. Many choose to compete (e.g., hoarding groceries and toilet paper). Others choose to cooperate (e.g., socially distancing and wearing masks). Why do some choose one strategy over the other? Might one's sense of cosmic justice impact their social behavior in times of uncertainty?

Uncertainty, in the sense that individuals have no information about how others will behave, is a complex issue that has been tackled across fields, including philosophy, computer science, economics, business management, sociology, and psychology. ${ }^{1-9}$ Research into uncertainty's effect on human behavior suggests a lack of consensus. Prior studies — although limited in number ${ }^{10}$ - have shown a dialectical struggle between cooperation and competition. Psychological research has yet to explore specifically how such 'cosmic uncertainty' — as defined in this study as the general feeling that worldly events are random, lacking order or fairness - affects social decision-making. Individuals who believe in randomness believe that good life behaviors may not result in good life outcomes. For instance, a person who donates money to charity is no more or less likely to contract a terminal illness than someone who does not donate to charity. Conversely, 'cosmic justice' is operationally defined as the general feeling that the world is a just, fair place where people generally get what they deserve. People who believe in cosmic justice are more inclined to believe that good things happen to good people and bad things happen to bad people. Thus, a person who donates money to charity may have a lower probability of contracting a terminal illness than someone who does not donate to charity. There is no single scale assessing a sense of cosmic justice, but there are many adjacent scales which will be introduced in the "Individual 
Differences" section below. First, it is worth examining people's general tendencies toward cooperative versus competitive behavior when situations do not explicitly call for one behavior or the other.

\section{Uncertainty and Cooperation}

Some studies suggest that people performing tasks with others default to cooperative behavior.1, 2 This means that humanity's altruistic tendencies tend to outweigh situational uncertainty. One reason to default to altruism is the concept of evolutionary fitness. ${ }^{11}$ Evolutionary psychology delves into how human and animal behavior tends to maximize the agent's evolutionary fitness - the ability to pass on our gene pool in the form of offspring. Our human ancestors were more likely to survive and pass along their genes if they cooperated with those who they are related to — such as offspring and family members. Early humans faced uncertainty; by working together, as opposed to competing with each other, they were able to hunt large game that could feed all.

There are, too, more practical purposes for cooperation. For example, people factor their reputation into their competitive or cooperative decision-making processes. ${ }^{12}$ When an individual is pitted against another person in multiple social situations, they tend to avoid giving negative impressions of themselves so as not to harm any potential future relationship. Indeed, in studies of game theory, participants tend toward cooperation and mutual respect - especially when they are aware that they will be playing multiple games in succession with that same partner. ${ }^{12}$ Thus, there is reason to believe that, under conditions of uncertainty, human behavior tends to favor cooperation over competition.

\section{Uncertainty and Competition}

However, other evidence suggests that uncertainty leads to more displays of competitive behavior. For instance, students in the classroom who are ranked against each other tend to withhold assistance from their peers. ${ }^{3}$ This competitive effect was seen when personal and peer rankings were unknown suggesting that uncertainty plays a significant role in the decision-making process. When resources are scarce and people do not know their likelihood of attaining those resources, they hold less regard for others. ${ }^{13}$

Similarly, fellow employees are more likely to compete rather than cooperate when payoffs are uncertain..$^{14}$ Employees at all levels in a performance-based compensation scheme who did not know how many 'winners' would be named competed against each other at a much higher rate. This willingness to enter into competitive behavior was strictly determined by the ambiguous payoff conditions for the employees.

Thus, the effect uncertainty has on social decision-making is not fully understood ${ }^{15}$ as researchers have arrived at competing conclusions.

\section{Individual Differences in World Beliefs}

To predict whether people will compete or cooperate in uncertain conditions, it may be helpful to examine the world beliefs people tend to carry into situations. In other words, do people generally believe in randomness or cosmic justice? The purpose of this study is to see whether individual differences in justice beliefs predict behavioral outcomes, namely cooperation or competition. Such individual differences include belief in a just world, ${ }^{16}$ ambiguity tolerance, ${ }^{17}$ and system justification. ${ }^{18}$ Belief in a just world is one's tendency to believe that people tend to get what they deserve. ${ }^{16}$ Ambiguity tolerance is defined as a measure of one's preference and comfortability with uncertain conditions. ${ }^{17}$ Similarly to just world beliefs, system justification measures how well individuals believe the current system — either cultural, societal, organizational, or economic — is inherently justified. ${ }^{18}$ Each of these individual differences relates to beliefs in cosmic justice. Specifically, people who score highly in belief in a just world and system justification and low in ambiguity tolerance would be more inclined to believe that good things tend to happen to good people.

\section{Current Study}

This study proposes that people who have a stronger inherent sense of justice may engage in more competitive (versus cooperative) behavior. Whereas cooperation tends to benefit the group, competition tends to benefit the individual. So, people with a strong sense of justice may feel entitled to the individual spoils of competition and attribute their positive outcomes to cosmic justice rather than their individual decision to compete. To examine this hypothesis, participants in this study completed a prisoner's dilemma game. The prisoner's dilemma game is a two-player game in which each player can choose to either cooperate 
or compete. ${ }^{19}$ However, the game is played without knowing what one's partner selected, and outcomes are mutually determined such that competing tends to benefit the individual and cooperating tends to benefit the group. Thus, the prisoner's dilemma game is a perfect vehicle to study competition and cooperation when outcomes are uncertain.

Participants in this study attended virtual game sessions where they played a simple prisoner's dilemma game with others they met at the sessions. Sessions were designed to maximize participants' uncertainty as to how others would behave. Two studies were conducted. This exploratory first study aimed to understand whether and how people's belief systems predicted their competitive versus cooperative behavior. The second study aimed to experimentally manipulate conditions of cosmic uncertainty by priming participants with a fair or unfair condition. Additionally, a religiosity index was added to the second study as people who are highly religious generally have a strong sense of cosmic justice. Thus, it may show similar or related results to the original three scales in situations of competition.

\section{METHODS AND PROCEDURES}

Study 1

Participants

Students were recruited from introductory psychology courses $(N=151)$ at a large midwestern university for course credit. Though demographic information was not collected for this sample, here demographics data from the subject pool at large is reported and from our own past studies. Subject pool participants are generally 61\% Female, 59.6\% White, and average 18.9 years old. Participants signed up for times resulting in groups of no less than three and no more than ten. Use of this sample was authorized by the authors' Institutional Review Board who deemed the current line of research exempt (HUM00189456).

\section{Materials}

Four constructs were used to create a Qualtrics survey: Belief in a Just World, ${ }^{16}$ Ambiguity Tolerance, ${ }^{17}$ System Justification, ${ }^{18}$ and the Positive and Negative Affect Scale (PANAS) ${ }^{20}$ (the PANAS was included as a distractor). Higher scores on the belief in a just world scale predict important attitudes such as a stronger belief in an individual's own ability to affect change on the world based on their actions. ${ }^{16} \mathrm{~A}$ high ambiguity tolerance score predicts that individuals will manage well in unfamiliar, ambiguous, or crosscultural situations. ${ }^{17}$ Higher scores on the system justification scale predict behaviors that uphold the current societal system. ${ }^{18}$ Internal reliability as measured by Cronbach's alpha was high for system justification $(\boldsymbol{\alpha}=.82)$ but low for belief in a just world ( $\boldsymbol{\alpha}$ $=.69)$ and ambiguity tolerance $(\boldsymbol{\alpha}=.61)$.

A task followed where written instructions asked participants to count specific letters (e.g., "e" and "g") on a page from a textbook. This task was also used in the prisoner's dilemma game as the assignment they would either split with (cooperate) or assign to (compete) their partner in the game.

\section{Design}

The independent variables were the three scales measuring beliefs about uncertainty, and the dependent variable was whether participants decided to cooperate or compete in the prisoner's dilemma game.

\section{Procedure}

Participants joined a Zoom video session on their home computers. A researcher guided the participants through the study. Participants were asked to mute their own audio and video. The Zoom chat feature was used to message information to participants to coordinate gameplay. After providing informed consent, participants worked through a series of counter-balanced scales (i.e., presented in a random order): belief in a just world, ambiguity tolerance, system justification, and the PANAS. Next, they completed a tedious task that involved counting letters on a textbook page (e.g., count all occurrences of the letter "E" on a page). This was intended to distract participants from drawing any connection between the survey content and the game play.

Next, participants were paired at random but not notified about the name of their partner so researchers could assign pairings even in odd group sizes. In the game, participants were told there was additional letter-counting that needed to be completed. Participants were told they had two options: they could assign their partner to do the task, or they could split the task between them. Participants were aware of the payout matrix (Table 1) but unsure what their payout would be as the payout is determined 
by both partners' choices — not unilaterally. Payouts, or consequences for the game, included zero, one, two, and four pages of letter-counting tasks similar to that which was completed as the distraction task. See Table 1 for the 'payout' structure presented to participants. After deciding, participants completed the letter-counting task per the payout matrix.

\begin{tabular}{ccc} 
Player & Matrix Result & Letter Counting Payout \\
\hline Player 1 & Split & 1 page \\
Player 2 & Split & 1 page \\
\hline Player 1 & Split & 4 pages \\
Player 2 & Assign & 0 pages \\
\hline Player 1 & Assign & 0 pages \\
Player 2 & Split & 4 pages \\
\hline Player 1 & Assign & 2 pages \\
Player 2 & Assign & 2 pages
\end{tabular}

Table 1. Prisoner's Dilemma Payout Matrix as shown to participants

Results

It was hypothesized that people high in aspects of cosmic uncertainty would be more likely to compete (vs. cooperate). Thus, a multiple logistic regression model was conducted to predict people's decision to assign or split from their belief in a just world, ambiguity tolerance, and system justification (Table 2). As this was an initial exploratory study, a liberal measure of statistical significance was accepted $(\boldsymbol{\alpha}=.10)$.

$\begin{array}{cc}\text { Odds Ratio } & \begin{array}{c}\text { Confidence } \\ \text { Interval }\end{array}\end{array}$

\begin{tabular}{lccc}
\hline BJW & 1.25 & $(0.68,2.31)$ & 0.46 \\
AT & 1.29 & $(0.54,3.04)$ & 0.55 \\
SJS & 1.42 & $(0.96,2.10)$ & 0.07
\end{tabular}

Table 2. Study 1 Results. Note: BJW = belief in a just world, AT = ambiguity tolerance, $\mathrm{SJS}=$ system justification scale

In Study 1, most people chose to cooperate (split the letter-counting work: 69.5\%) rather than compete (assign the letter-counting work: 31.5\%). Neither ambiguity tolerance nor belief in a just world predicted people's decisions to compete or cooperate (both $p$ $>$.10). However, initial evidence was found that there is a correlation between a participant's system justification scale score and 
their decision to compete $(p=0.07)$. People who scored highly in system justification were more likely to assign letter-counting work to their fellow participant (Figure 1). Although only marginally significant by conventional standards, this preliminary finding warrants further investigation.

Study 1 carried several limitations. After analyzing Study 1's results, it was concluded that low internal reliability in the belief in a just world and ambiguity tolerance scales could be driving (null) results. In other words, these individual differences may not have been optimally measured. Additionally, an unmeasured individual difference (i.e., religiosity) was identified as a likely driver of justice beliefs. Like people high in system justification, highly religious people generally share a strong sense of cosmic justice. So, highly religious people may also behave in similarly competitive ways. Yet, no religiosity measure was included in Study 1 . Finally, Study 1 measured a dispositional sense of cosmic justice but did not manipulate perceptions of cosmic justice. Study 2 was designed to address these limitations.

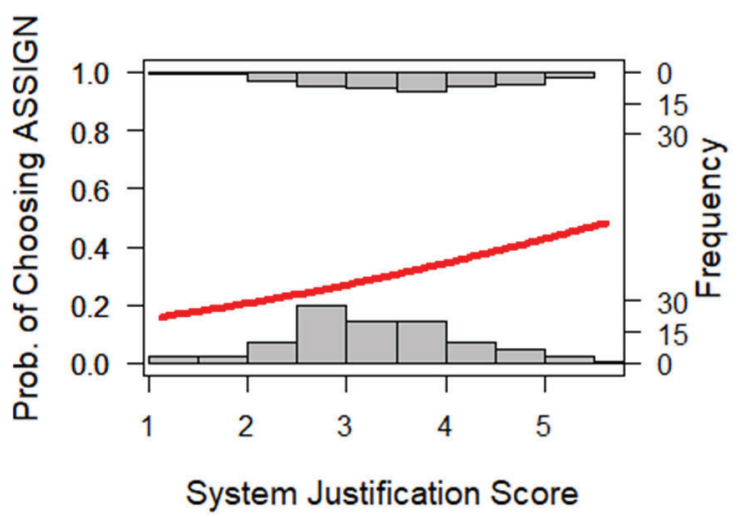

Figure 1. System Justification Scale Results from Study 1

Study 2

Participants

For the second study, students were recruited from introductory psychology courses $(N=135)$ at a large midwestern university for course credit. Participants were 55\% Male and 45\% Female. The racial background was 63\% White, 18\% Asian, and 15\% Other. Participants ranged from 17 to 35 years old $(M=19.3, S D=1.8)$. Due to time limitations, some participants were unable to answer demographic questions at the end of the study (14 no response to gender and 16 no response to race; percentages reported exclude non-respondents). Participants signed up for times resulting in groups of no less than three and no more than ten.

\section{Materials}

Study 2 tasked participants to complete scales for five constructs: Global Belief in a Just World, ${ }^{21}$ Ambiguity Tolerance, ${ }^{22}$ System Justification, ${ }^{18}$ a Religion Index, ${ }^{23}$ and a distraction task (completing a Positive Negative Affect scale). ${ }^{20}$ Note the changes from Study 1: a revised (global) belief in a just world scale, ${ }^{21}$ a revised ambiguity tolerance scale, ${ }^{22}$ and the addition of a religion index. ${ }^{23}$ The revised scales were included to improve internal reliability (i.e., improve measurement). The religion index was included to explore another possible basis of behavior under uncertain conditions. Internal reliability as measured by Cronbach's alpha was high for belief in a just world $(\boldsymbol{\alpha}=.89)$, ambiguity tolerance $(\boldsymbol{\alpha}=.82)$, system justification $(\boldsymbol{\alpha}=.84)$, and religiosity $(\boldsymbol{\alpha}=.91)$.

The letter-counting task was identical to that used in Study 1.

Design

Study 2 aimed to experimentally manipulate cosmic uncertainty. Participants were randomly assigned to either a fair or unfair condition. The fair condition asked participants to write a detailed paragraph about, "a time in your life when you felt the world 
was very fair to you and that you generally got what you deserved." The unfair condition asked participants to write a detailed paragraph about, "a time in your life when you felt the world was very unfair to you and that you generally did NOT get what you deserved." These paragraphs were designed to manipulate participants' sense of cosmic fairness and order. This design was adapted from a commonly used power manipulation wherein participants write about a time they experienced high or low power. ${ }^{24}$ Thus, independent variables in Study 2 included the experimental condition and the four scales measuring beliefs about uncertainty. The dependent variable was whether participants decided to cooperate or compete in the prisoner's dilemma game.

\section{Procedure}

As in Study 1, participants were guided by a researcher over Zoom. After providing informed consent, participants worked through a series of counter-balanced scales: belief in a just world, ambiguity tolerance, system justification, a religious index, and a distraction scale. Next, they completed one page of letter-counting as in Study 1 (which introduced participants to the tedious work they would later assign or split). This was followed by a writing task about a fair or unfair experience in the participant's own life. Next, participants went through the same procedure as Study 1's prisoner's dilemma type game: Participants could assign their partner to do additional letter-counting, or they could split the counting between them.

\section{Results}

Study 2 results were expected to replicate our Study 1 results in that people high in facets of cosmic uncertainty would be more likely to compete (vs. cooperate). Thus, a multiple logistic regression model was conducted that predicted people's decision to assign or split from their belief in a just world, ambiguity tolerance, system justification, and religiosity (Table 3). The researchers also examined whether the fairness manipulation made participants more or less likely to compete. For these confirmatory analyses, a more conservative threshold of statistical significance was adopted $(\boldsymbol{\alpha}=.05)$. Finally, exploratory analyses were conducted to assess whether demographic variables such as age or gender predicted a participant's decision to compete (or cooperate). For these exploratory analyses, a more liberal threshold of statistical significance was used $(\boldsymbol{\alpha}=.10)$

Odds Ratio 95\% Confidence Interval p-value

\begin{tabular}{|c|c|c|c|}
\hline BJW & 1.82 & $(1.16,2.97)$ & $0.01 *$ \\
\hline AT & 1.51 & $(0.71,3.33)$ & 0.29 \\
\hline SJS & 1.80 & $(1.22,2.74)$ & $0.004 * *$ \\
\hline RI & 0.93 & $(0.68,1.28)$ & 0.67 \\
\hline
\end{tabular}

Table 3. Study 2 Results. Note: $\mathrm{BJW}=$ belief in a just world, $\mathrm{AT}=$ ambiguity tolerance, $\mathrm{SJS}=$ system justification scale, $\mathrm{RI}=$ religious index

As in Study 1, most people chose to cooperate (split the letter-counting work: 69.6\%) rather than compete (assign the lettercounting work: $31.4 \%$ ). The association between system justification and a participant's decision to choose to "Assign" ( $p<0.05)$ was replicated. Additionally, there was evidence that people with a higher belief in a just world were more likely to assign lettercounting work $(p<0.05)$. That is, people who scored higher in belief in a just world and system justification were more likely to choose the competitive option of "assigning" work to their peer. As in Study 1, no evidence supported the notion that ambiguity tolerance had any meaningful bearing on a participant's decision in the binary prisoner's dilemma game $(p=0.29)$, nor was there evidence to suggest that religiosity plays a role in this competitive decision $(p=0.67)$.

No evidence was found that experimentally manipulating participants' feelings of cosmic justice impacted their competitive 
decision, nor did it have any interaction with any other scale (Condition $\mathrm{p}=0.61$; Condition \& Belief in a Just World $p=0.94$; Condition \& System Justification $p=0.94$; Condition \& Religiosity $p=0.52)$.

Age was not a significant predictor of a participant's decision to compete or cooperate $(p=0.63)$. However, the data showed quite the opposite for gender $(p<0.05)$. Gender played a significant role in the decision-making process and was correlated with certain personality constructs. When conducting Welch T-tests to examine gender differences between scales, evidence was found that Men $(M=3.59)$ scored higher than women $(M=3.00)$ in belief in a just world $(p<.001)$, marginally higher $(M=3.30)$ than women $(M=3.15)$ in ambiguity tolerance $(p=.10)$, and higher $(M=3.93)$ than women $(M=3.01)$ in system justification $(p<$ $.001)$. Men $(M=2.69)$ and women $(M=2.71)$ did not differ in religiosity $(p=.92)$. Further logistic regression analyses were conducted to assess whether belief in a just world and system justification predicted decisions to compete/cooperate controlling for gender. Both belief in a just world $(p=0.07)$ and system justification $(p=0.08)$ were marginal predictors of competitive behavior even controlling for gender.

\section{DISCUSSION}

Across two studies, the overwhelming majority of people chose to cooperate in the face of uncertainty. However, this trend was reversed among individuals who had a strong, stable sense of cosmic certainty — that is, people who believed the world was fair and the system was just tended to compete. This could be due to participants' beliefs about how society works. For instance, those that score highly on system justification are more likely to strongly agree with statements such as 'everyone has a fair shot at wealth and happiness' or 'society is set up so that people usually get what they deserve' ${ }^{25}$ If an individual scores highly on system justification, then it is likely that they believe that they deserve any positive outcomes they receive, as good things only happen for good people. If something drastic were to change in the society that currently serves them well, then they would generally be worse off. Those that believe that the system is working in their favor may experience less (if any) guilt that comes with knowing others are less fortunate. It is worth noting that these effects held for both men and women and were not dependent on participants' ages.

Our findings contrasted to prior studies that suggest that uncertainty leads to competitive behavior. In the classroom study that ranked students, under uncertain conditions students tended to resort to selfish, competitive behavior so as to not jeopardize their own position in the class rankings. ${ }^{3}$ In our study, most of our participants chose to cooperate. This pattern of results is more consistent with research showing that people tend to cooperate to improve their reputation for future interactions. ${ }^{12}$ However, as participants in the current study played only a single round of the game, this study suggests that reputation-building is not the only driver of cooperation. As one participant in our study stated, they saw cooperation as the 'fair' option and 'didn't want the other person to have so much work left.'

\section{Limitations and Future Directions}

Our research involved several limitations. Our study's first limitation was that our ambiguity tolerance and belief in a just world scales yielded low internal reliability scores in Study 1. This limitation was addressed in Study 2 in the form of revised belief in a just world ${ }^{21}$ and ambiguity tolerance ${ }^{22}$ scales with a history of higher internal reliability. Indeed, internal reliability improved for both belief in a just world ( $\boldsymbol{\alpha}=0.69$ in Study 1; $\boldsymbol{\alpha}=0.89$ in Study 2$)$ and ambiguity tolerance $(\boldsymbol{\alpha}=0.61$ in Study $1 ; \boldsymbol{\alpha}=0.82$ in Study 2). Future research may consider replicating these findings with the revised scales. Alternatively, as these scales were intended to measure the novel construct of "cosmic justice," this construct may deserve its own scale rather than be measured through these proxy scales.

Another limitation this study ran into is that, due to COVID-19, all research had to be conducted online through platforms such as Qualtrics and Zoom. Individual participants never saw or interacted with each other as they would in a classroom or workplace. Similarly, participants did not know who they would play the competitive behavior game against. Although these decisions likely bolster internal validity, they limit external validity when applying these concepts to 'real-world' cases. In the 'real world,' people are expected to exhibit even more cooperative behavior, as a number of social pressures manifest when individuals are making decisions face-to-face. ${ }^{26}$ For instance, a classic study shows that people are more inclined to help others (1) when they empathize with the target and (2) when they have to see the ramifications of their actions. ${ }^{24}$ 
Though this research is not definitive, it opens the door for future research to further investigate this relationship. More specifically, researchers should work to better isolate and understand a causal relationship between one's system justification score and their projected behavior. Study 2 attempted to experimentally manipulate perceptions of systemic fairness to little success. Writing one paragraph may not be enough to manipulate a participant's belief in cosmic justice. Future studies may use a stronger manipulation. Such manipulations could include longer free-response essay questions about times when participants were treated fairly or unfairly by the "system" or "society at large." Alternatively, researchers could implement fake news articles or videos that portray examples of society's parity or inequality.

\section{Theoretical and Practical Implications}

Though decision uncertainty has been studied at length, 1, 3, 9, 10,15, 27 cosmic uncertainty, as defined in this study, is a nuanced approach to explain human competitive behavior. The findings suggest that in the face of uncertainty, people who have a stable sense of cosmic justice - i.e., those high in system justification and belief in a just world — tend to compete. Further research is needed to determine the bounds of this effect and how task definitions influence people's perceptions of uncertainty in social games.

This study has further societal implications. Though these concepts may appear abstract, there are real decisions people make in the face of uncertainty on a daily basis. Understanding individual differences in beliefs about cosmic fairness could lead to understanding people's decisions to quarantine, wear masks, get vaccinated, or socially distance. In order for the world to be put back together again, it is vital to understand the inner workings of how decisions are made based on underlying individual differences in beliefs.

\section{ACKNOWLEDGEMENTS}

I'd like to give a generous thanks to Zach Reese as this manuscript would not have been possible without his excellent guidance and mentoring at every step of the way. I'd also like to thank Dr. Seifert and Dr. Garcia for their help with the overall direction of the project. This research was conducted through Michigan's Social Comparison and Close Relationships lab and I am extremely grateful for all the research assistants' help with data collection. Thank you to my family and friends for supporting me every step of the way.

\section{REFERENCES}

1. Torii, T., \& Hidaka, S. (2015) Mutual cooperation out of greedy learners: Prisoner's dilemma under uncertainty. Cognitive Studies: Bulletin of the Japanese Cognitive Science Society, 22(3), 341-355. https:/ / doi.org/10.11225/jcss.22.341

2. Zuckerman, M. (1975) Belief in a just world and altruistic behavior. Journal of Personality and Social Psychology, 31(5), 972-976. https:// doi.org/10.1037/ b0076793

3. Burleigh, T. J., \& Meegan, D. V. (2018) Risky prospects and risk aversion tendencies: Does competition in the classroom depend on grading practices and knowledge of peer-status? Social Psychology of Education: An International Journal, 21(2), 323-335. https:// doi.org/10.1007/s11218-017-9414-x

4. Taroni, F., Bozza, S., Biedermann, A., \& Aitken, C. (2016) Dismissal of the illusion of uncertainty in the assessment of a likelihood ratio. Law, Probability and Risk, 15(1), 1-16. https:/ / doi.org/10.1093/ /pr/mgv008

5. Braun, P., Cuzzocrea, A., Leung, C. K., \& Pazdor, A. G. M. (2018) Item-centric mining of frequent patterns from big uncertain data. Procedia Computer Science, 126, 1875-1884. https:// doi.org/10.1016/j.procs.2018.08.075

6. Baron, D. P. (1970) Price Uncertainty, Utility, and Industry Equilibrium in Pure Competition. International Economic Review, 11(3), 463-480. https:/ / doi.org/10.2307/2525325

7. Wernerfelt, B., \& Karnani, A. (1987) Competitive strategy under uncertainty. Strategic Management Journal, 8(2), $187-194$. bttps:/ / doi.org/10.1002/smj.4250080209

8. Zinn, J. O. (2009) The sociology of risk and uncertainty: A response to Judith Green's "Is it time for the sociology of health to abandon 'risk?" Health, Risk \& Society, 11(6), 509-526. bttps:/ / doi.org/ 10.1080/13698570903329490

9. Danczak, A., \& Lea, A. (2017) The psychology of uncertainty in difficult decisions. InnovAiT, 10(8), 466-472. https:/ / doi.org/ 10.1177/1755738017709034

10. Sleesman, D. J., \& Conlon, D. E. (2017) Encouraging prosocial decisions: The role of fairness salience and uncertainty. Journal of Behavioral Decision Making, 30(2), 502-515. https:/ / doi.org/ 10.1002/ bdm.1970 
11. Buston, P. M., \& Balshine, S. (2007) Cooperating in the face of uncertainty: A consistent framework for understanding the evolution of cooperation. Behavioural Processes, 76(2), 152-159. bttps:// doi.org/10.1016/j.beproc.2007.01.020

12. Cooper, R., DeJong, D. V., Forsythe, R., \& Ross, T. W. (1996) Cooperation without Reputation: Experimental Evidence

from Prisoner's Dilemma Games. Games and Economic Behavior, 12(2), 187-218. https://doi.org/10.1006/game.1996.0013

13. Hardin, G. (1968) The Tragedy of the Commons. Science, 162(3859), 1243-1248. DOI: 10.1126/science.162.3859.1243

14. Balafoutas, L., \& Sutter, M. (2019) How Uncertainty and Ambiguity in Tournaments Affect Gender Differences in Competitive Behavior, 118, 1-13.

15. Vives, M.-L., \& Feldman-Hall, O. (2018) Tolerance to ambiguous uncertainty predicts prosocial behavior. Nature Communications, 9, 1-9. bttps:// doi.org/10.1038/s41467-018-04631-9

16. Rubin, Z., \& Peplau, A. (1973) Belief in a Just World and Reactions to Another's Lot: A Study of Participants in the National Draft Lottery1. Journal of Social Issues, 29(4), 73-93. https:/ / doi.org/10.1111/j.1540-4560.1973.tb00104.x

17. Herman, J. L., Stevens, M. J., Bird, A., Mendenhall, M., \& Oddou, G. (2010) The Tolerance for Ambiguity Scale: Towards a more refined measure for international management research. International Journal of Intercultural Relations, 34(1), 58-65. bttps:/ / doi.org/10.1016/j.ijintrel.2009.09.004

18. Jost, J. T., \& Banaji, M. R. (1994) The role of stereotyping in system-justification and the production of false consciousness. British Journal of Social Psychology, 33(1), 1-27. https:// doi.org/10.1111/j.2044-8309.1994.tb01008.x

19. Doebeli, M. and Hauert, C. (2005), Models of cooperation based on the Prisoner's Dilemma and the Snowdrift game. Ecology Letters, 8: 748-766. https:// doi-org.proxy.lib.umich.edu/10.1111/j.1461-0248.2005.00773.x

20. Watson, D., Clark, L. A., \& Tellegen, A. (1988) Development and validation of brief measures of positive and negative affect: The PANAS scales. Journal of Personality and Social Psychology, 54(6), 1063-1070. bttps:// doi.org/ 10.1037/0022-3514.54.6.1063

21. Lipkus, I. (1991) The construction and preliminary validation of a global belief in a just world scale and the exploratory analysis of the multidimensional belief in a just world scale. Personality and Individual Differences, 12(11), 1171-1178. bttps:/ / doi.org/10.1016/0191-8869(91)90081-L

22. McLain, D. L. (2009) Evidence of the Properties of an Ambiguity Tolerance Measure: The Multiple Stimulus Types Ambiguity Tolerance Scale-II (MSTAT-II). Psychological Reports, 105(3), 975-988. bttps:/ / doi.org/ 10.2466/PR0.105.3.975-988

23. Koenig, H. G., \& Büssing, A. (2010) The Duke University Religion Index (DUREL): A Five-Item Measure for Use in Epidemiological Studies. Religions, 1(1), 78-85. https:// doi.org/10.3390/ rel1010078

24. Galinsky, A. D., Magee, J. C., Inesi, M. E., \& Gruenfeld, D. H. (2006) Power and Perspectives Not Taken. Psychological Science, 17(12), 1068-1074. https:// doi.org/10.1111/j.1467-9280.2006.01824.x

25. Roccato, M. (2014) Measurement properties of the system justification scale: A Rasch analysis. TPM - Testing, Psychometrics, Methodology in Applied Psychology, 3, 467-478. https:/ / doi.org/10.4473/TPM21.4.7

26. Toi, M., \& Batson, C. D. (1982) More evidence that empathy is a source of altruistic motivation. Journal of Personality and Social Psychology, 43(2), 281-292. https:/ / doi.org/10.1037/0022-3514.43.2.281

27. Schulze, C., van Ravenzwaaij, D., \& Newell, B. R. (2015) Of matchers and maximizers: How competition shapes choice under risk and uncertainty. Cognitive Psychology, 78, 78-98. https:// doi.org/10.1016/j.cogpsych.2015.03.002

\section{ABOUT STUDENT AUTHOR}

Duncan Drewry was an undergraduate student at the University of Michigan at Ann Arbor and graduated with a B.A. in Cognitive Science with distinction and high honors. While at Michigan he also majored in Spanish and was a member of the Social Comparisons and Close Relationships lab working on Psychology research.

\section{PRESS SUMMARY}

How do our underlying beliefs about fairness, justice, and ambiguity influence our behavior? Does it lead us to cooperate or compete? Little research has examined how individual differences between people moderate cooperative and competitive behavior in the face of uncertainty. This study proposes that a stable sense of justice may, ironically, lead to more competitive behavior. Specifically, people who score highly in belief in a just world, system justification, and religiosity may be more inclined to compete rather than cooperate because they see themselves as good and believe they deserve positive outcomes. Our results 
show that people tended to cooperate, but those who believe the current social system is fair and that the world is just were more likely to compete. In other words, people with a strong sense of cosmic justice would be more likely to exhibit competitive behavior under uncertain conditions. 